\title{
CHARACTERIZATION OF NEW EXCIMER PUMPED UV LASER DYES I. $p$-TERPHENYLS
}

\author{
D. J. SCHNEIDER, D. A. LANDIS, P. A. FLEITZ \\ and C. J. SELISKAR $\dagger$
}

Chemistry Department, University of Cincinnati, Cincinnati, Ohio 45221-0172

\section{J. M. KAUFFMAN}
Chemistry Department, Philadelphia College of Pharmacy and Science, 43rd Street and Kingsessing Mall, Philadelphia, PA, 19104-4495
R. N. STEPPEL

Exciton Inc., P.O. Box 31126, Overlook Station, Dayton, Ohio 45431

(Received 25 September, 1990; in final form 22 October, 1990)

\begin{abstract}
The performance characteristics of a series of new excimer pumped ultraviolet dyes are presented. Chemical structure modifications which influence dye performance are discussed. An evaluation of several alternative solvents shows that $p$-dioxane remains the solvent of choice based on dye performance. The influence of the cover gas in the dye circulator was examined and results are presented to show how dye performance can greatly depend on this factor.
\end{abstract}

KEYWORDS: Laser dye, excimer pumped, ultraviolet, solvent.

\section{INTRODUCTION}

The popularity of the $308 \mathrm{~nm} \mathrm{XeCl} \mathrm{excimer} \mathrm{laser} \mathrm{as} \mathrm{a} \mathrm{dye} \mathrm{pump} \mathrm{accentuates} \mathrm{the} \mathrm{need}$ for robust dye molecules that are more stable as well as more efficient under short wavelength excitation..$^{1-7}$ In addition, since ease of use is an important practical aspect of dye choice, enhanced solubility of the dyes in useful solvents becomes important in designing new laser materials. Among the most stable UV laser dyes for $308 \mathrm{~nm}$ excitation are the dye classes based on the oligophenylenes $p$-terphenyl ${ }^{1,3}$ and $p$-quaterphenyl. ${ }^{4-6}$ In this paper we briefly report results of our work on new excimer pumped $p$-terphenyl laser dyes. The behavior of four of the dyes (Table 1 , dyes $8,11,12,13$ ) under flashlamp pumping has been described previously. ${ }^{8}$

\section{EXPERIMENTAL DETAILS}

\section{Laser Instrumentation}

The laser instrumentation consisted of Lambda Physik EMG 201 MSC XeCl excimer (unstable resonator optics) and FL3002E dye lasers. The dye laser circulator 
D. J. SCHNEIDER ET $A L$.

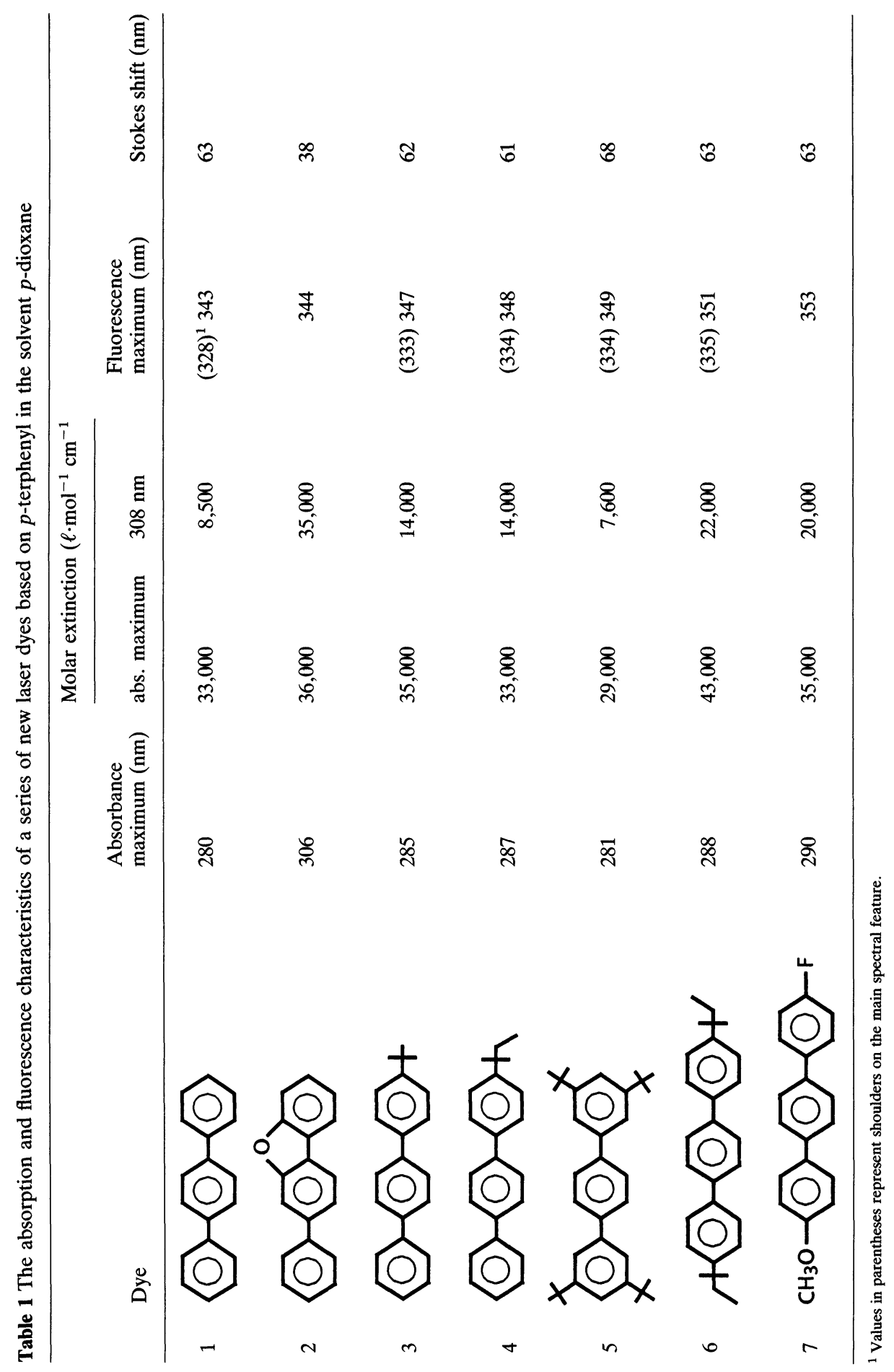


NEW UV LASER DYES

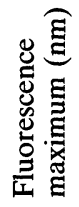

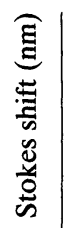

6

\&

$\%$

$\infty$

8

ตั

m

స్లి

స్

ల్ల

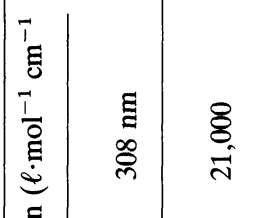

ह్ర

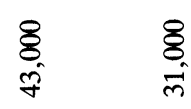



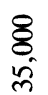

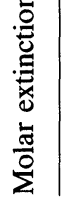

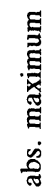

క్ర్రి

ह్

$\begin{array}{ll}8 & 8 \\ 8 & 8\end{array}$

$\underset{8}{8}$

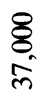

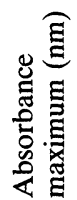

ลี

$\frac{\infty}{m}$

$\frac{0}{m}$

ภู

ฉู

ช్ల

这

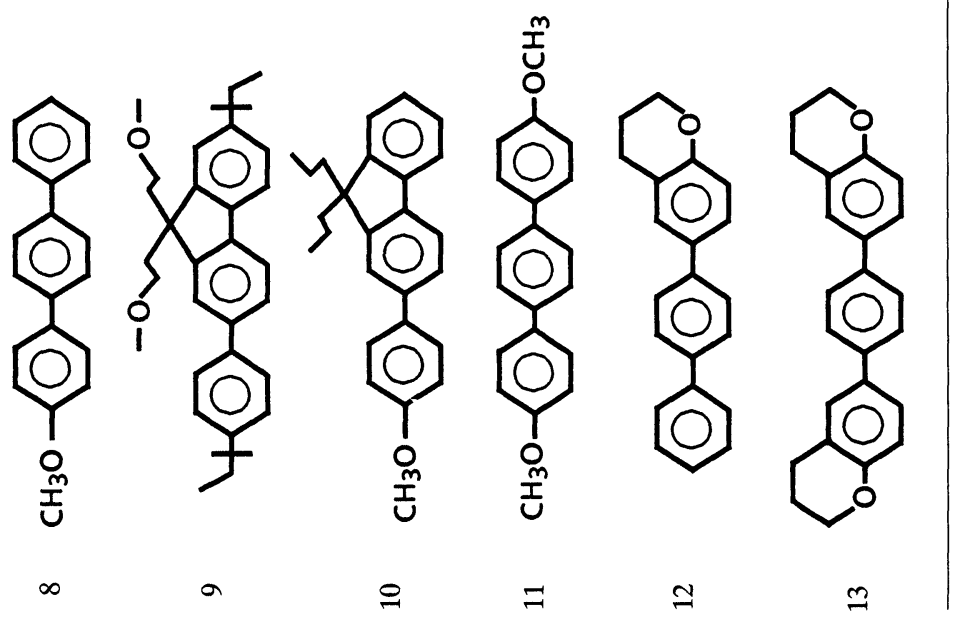


reservoirs for both the oscillator/preamplifier and amplifier stages consisted of the small Lambda Physik dye circulators (100-200 ml volume) both fitted with high speed flow cells and Balston filters.

The dye laser was typically pumped with half $(130-200 \mathrm{~mJ} /$ pulse $)$ of the excimer laser output by employing an anti-reflection coated beamsplitter. Excimer pulse energies were measured using a Scientech volume absorber head (No. 380405). Dye laser pulse energies, at the exit of the dye laser, were measured by expanding the laser beam and directing it onto a Gentec, Inc. (Model ED-200) or a Scientech calibrated detector.

\section{Methods of Measurement}

The optimum dye concentration was obtained by working from a concentrated dye stock solution prepared with an optical density of 20 per centimeter at $308 \mathrm{~nm}$. The initial working volumes in the circulators were prepared by using a portion of this stock solution directly (oscillator/preamplifier stage) and adding two parts of solvent by volume to the stock solution (amplifier stage) as recommended by Lambda Physik.

The dye laser wavelength was positioned in the region of expected dye emission and then manually toggled to locate the wavelength position of maximum laser gain. From known initial circulator solution volumes, dilutions by sequential quantitative solvent additions were made while maintaining the 3 to 1 concentration ratio between the oscillator/preamplifier and the amplifier stages of the dye laser. Optimum concentration values reported refer to the concentration of the dye in the oscillator/preamplifier stage.

The final dye parameters, wavelength of maximum laser gain, tuning range and conversion efficiency were all determined in the concentration region of optimum dye performance. The tuning curve of each dye was obtained by scanning the dye laser through the gain profile of the dye and computer logging the laser pulse energies using the boxcar integrator. In this paper we report both the useful region of dye gain (the full tuning range), and the full-width at half-maximum (fwhm) tuning range of dye gain.

The dye conversion efficiency was measured by recording the ratio of the dye laser pulse energy at the exit of the dye laser to the excimer pulse energy at the dye laser entrance. No corrections have been made for internal light losses within the dye laser. This method of defining the conversion efficiency, while differing from some previous authors' methods, ${ }^{1-6}$ has the advantage of being directly useful for a common commercial instrument. As a result of neglecting internal light losses, our values for dye efficiencies are somewhat lower than certain other investigators values where common measurements can be compared.

Dye stability, i.e. the half-life, $E_{1 / 2}$, of each laser dye was defined ${ }^{3,5,6}$ as the total excimer laser pulse energy at $308 \mathrm{~nm}$ required to degrade the dye laser pulse energy to $50 \%$ of its initial optimum value. These half-life values were determined directly from experiment, i.e. no extrapolation procedure was used to determine these values. Between measurements of dye laser pulse energies in a degradation experi- 
ment, the excimer laser was typically operated at $60 \mathrm{~Hz}$ to reduce the amount of time a degradation study would take. A reduced exposure schedule was substituted for the few very unstable dyes reported on in this paper.

In an effort to carefully control the half-life measurements, a gas circulation system for the circulators was constructed which allowed different cover gases to be used. The circulation system consisted of a fritted disc gas bubbler (to equilibrate the circulated cover gas) and the appropriate $1 / 8$ th inch nylon tubing and stainless fittings to interconnect the two circulators while under active gas circulation. In the reported cover gas studies, flow rates were maintained at $30 \mathrm{ml} / \mathrm{min}$ and all measurements were taken after a $10 \mathrm{~min}$ initial equilibration time. In most instances, the cover gas was not circulated.

Fluorescence spectra, corrected for instrument spectral response, were obtained as previously described. ${ }^{8}$

\section{Chemicals and Dyes}

Solvents, freshly opened, were used as purchased as Analytical Reagents from Fisher Chemical Company. Selected test results were also obtained with Baxter B\&J Grade solvents and were found to be comparable to those obtained with Fisher solvents. The syntheses of most of the new dyes used in this study have been described in previous works. ${ }^{8,9,10}$ The dye $p$-terphenyl was obtained from Exciton, Inc.

Circulator cover gases consisted of ambient Cincinnati air, commercial bottled air (mixture of $\mathrm{N}_{2}$ and $\mathrm{O}_{2}$ ), Matheson High Purity argon and nitrogen, and commercial oxygen.

\section{RESULTS AND DISCUSSION}

The identification of the dyes examined in this study and the associated physical properties of them are summarized in Tables 1 and 2. The laser dyes have been grouped in the order of increasing laser (maximum) wavelength. Since, in general, the laser intensity maximum coincides with the wavelength maximum of the fluorescence curve, this is also the order of the grouping in Tables 1 and 2. Absorbance, fluorescence and laser gain curves for several typical dyes are also shown in Figures $1-3$.

\section{Absorption and Fluorescence Spectra}

The laser dyes 3, 4 and 6-13 in Table 1 represent chemical substitution on the long axis of the molecule (at the 4 and 4 " positions) with electron donating groups. Such substitutions produce red shifts in the absorbance maxima of the longest wavelength transition, $S_{0} \rightarrow S_{1}$, as would be expected for the polarization (long axis) of this transition. In addition, constraining two of the phenyl rings to be planar by ring-bridging (dyes 6,$9 ; 8,10$ ) results in a similar red shift in the longest wavelength 
D. J. SCHNEIDER ET $A L$.

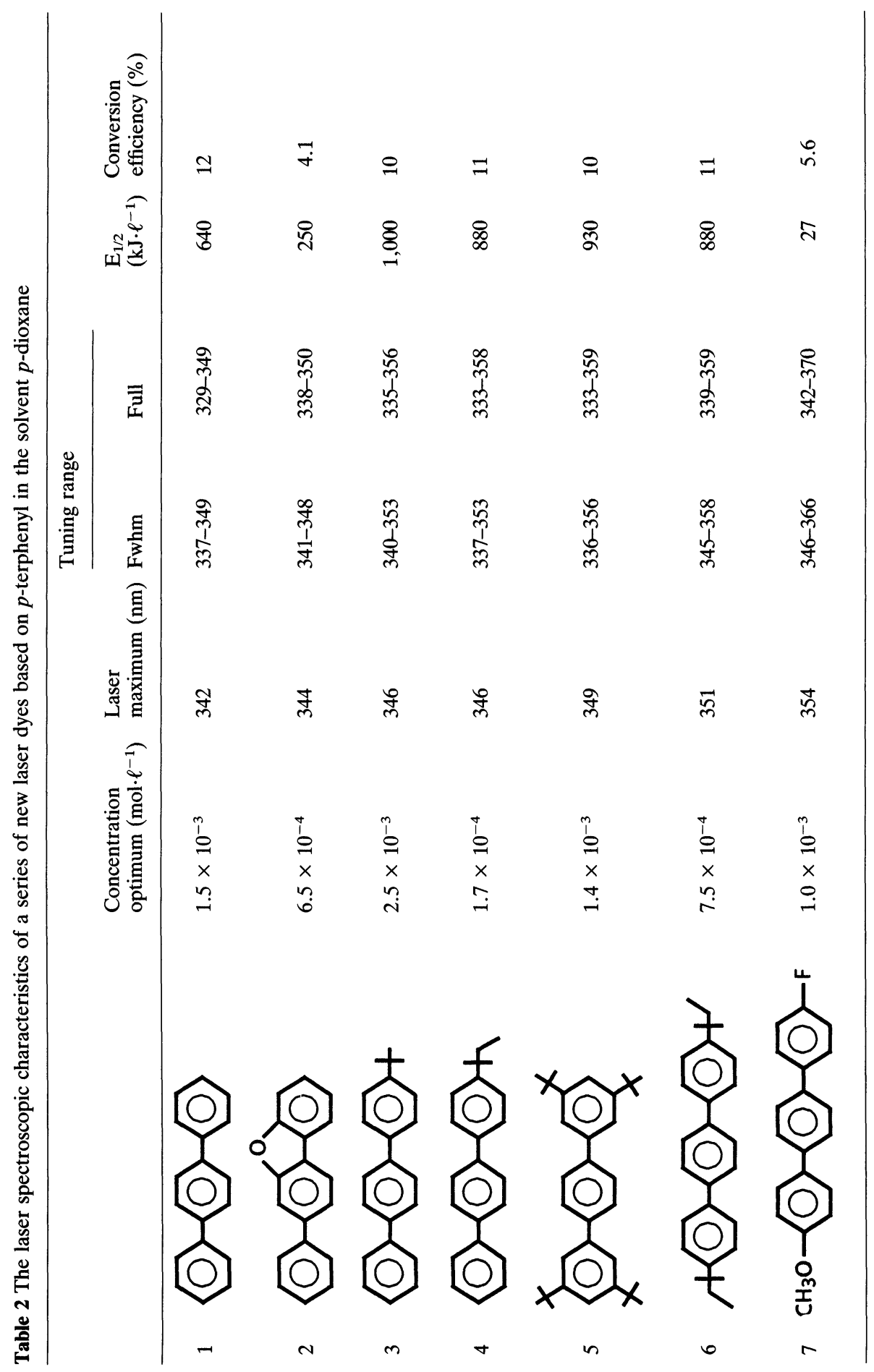


NEW UV LASER DYES

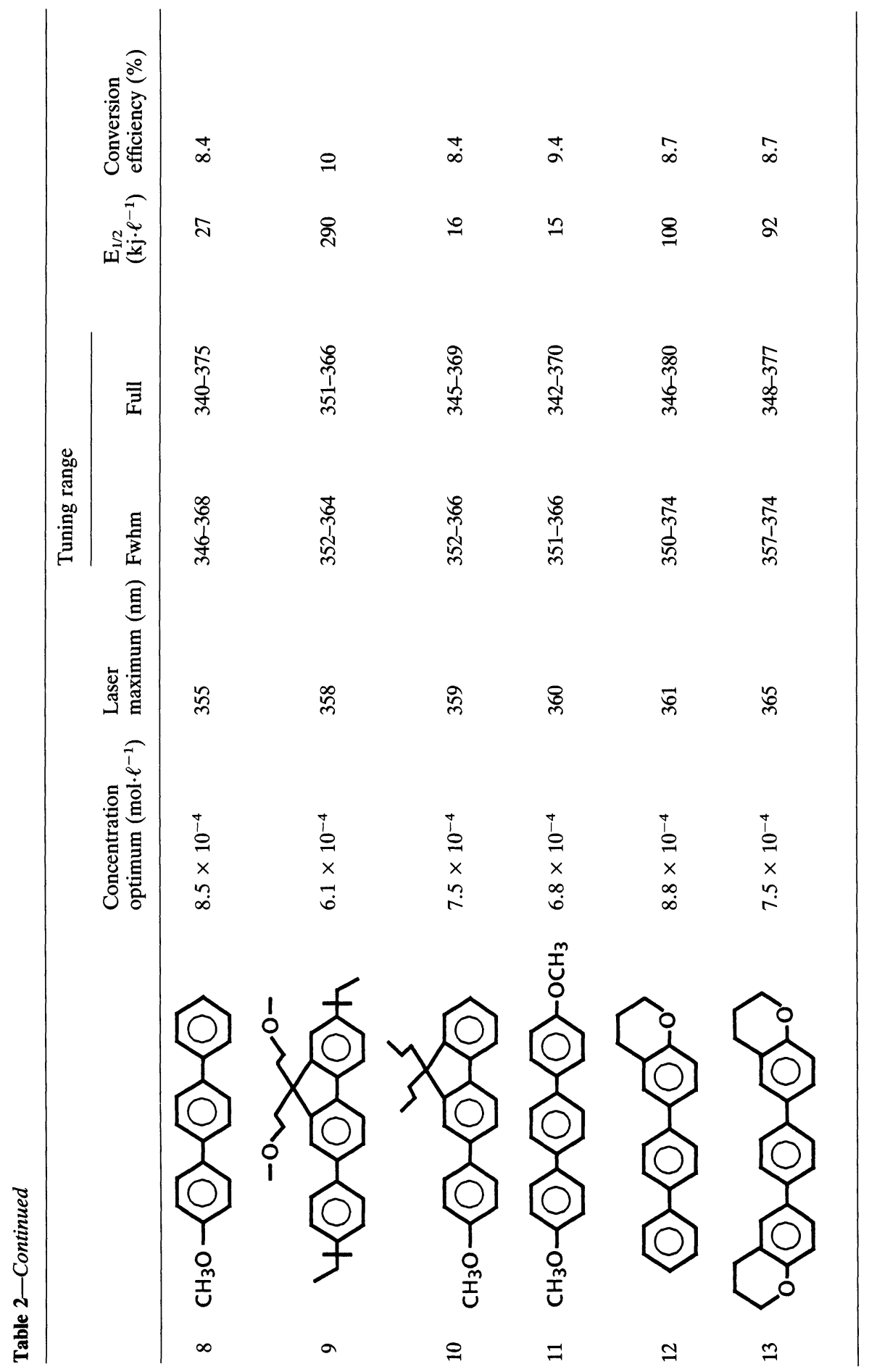


56

D. J. SCHNEIDER ET $A L$.

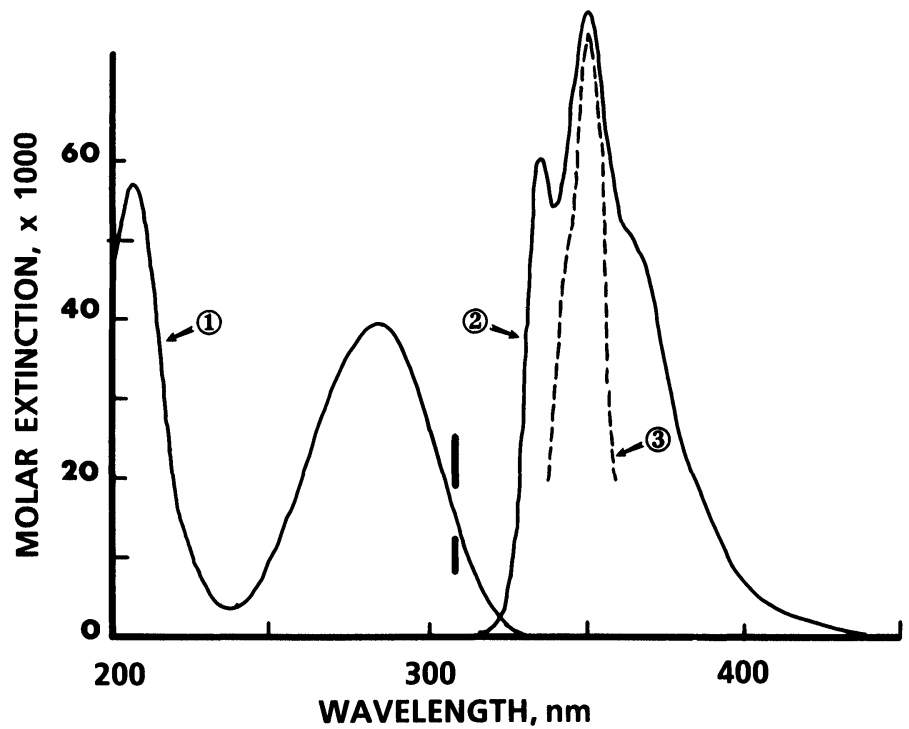

Figure 1 The molar extinction (curve 1), fluorescence (curve 2) and laser gain (curve 3) spectra of dye 6 in cyclohexane, $p$-dioxane and $p$-dioxane, respectively.

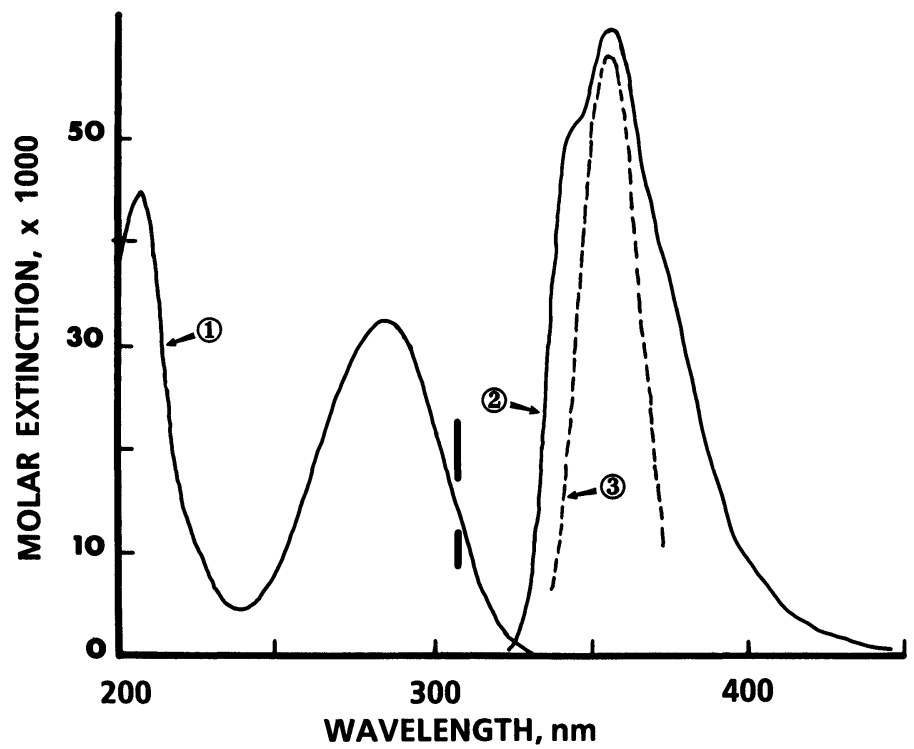

Figure 2 The molar extinction (curve 1), fluorescence (curve 2) and laser gain (curve 3 ) spectra of dye 8 in cyclohexane, $p$-dioxane and $p$-dioxane, respectively. 


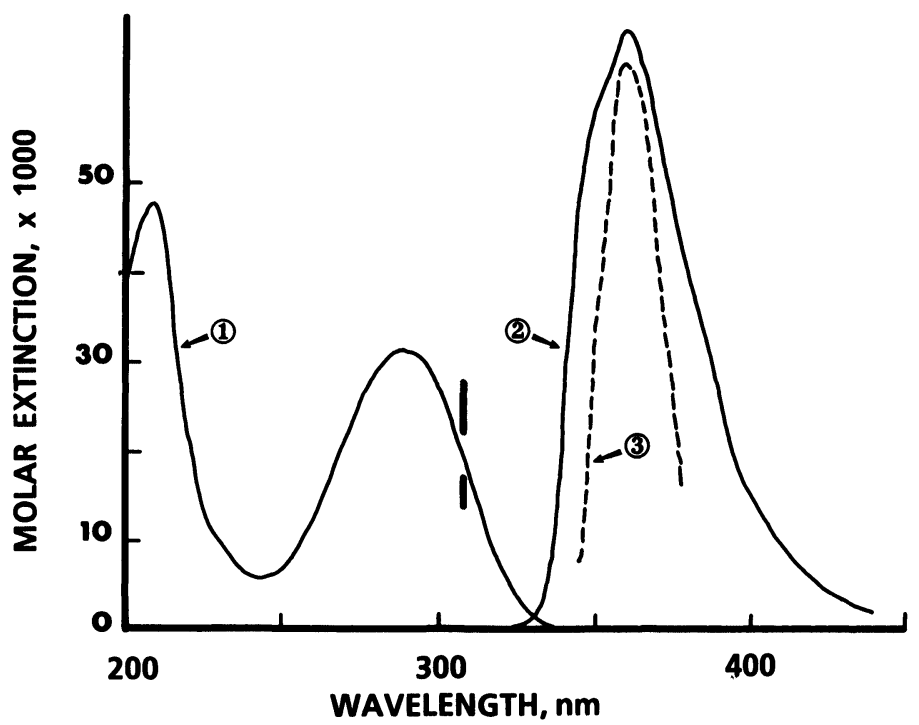

Figure 3 The molar extinction (curve 1), fluorescence (curve 2) and laser gain (curve 3) spectra of dye 12 in cyclohexane, $p$-dioxane and $p$-dioxane, respectively.

transition. Rigidization of the exocyclic ether functions ${ }^{8}$ by chemical modification (see dyes 8 versus 12 and dyes 11 versus 13) produces a slight but not consistent shift in this transition. Fluorination at the 4 " position (compare dyes 7 and 8 ) produces a small blue shift.

The fluorescence curves (see, for example, Figures 1-3) are marked by definite vibrational structure which is more pronounced in certain cases (dyes 1, 3-6, 10,11) and less so in others. Without exception, the fluorescence maxima are also the laser gain curve maxima for the dyes discussed. Vibrational structure in the fluorescence is not consistently reflected in the overall shape of the gain curves. The fluorescence quantum yields for all these dyes are high, i.e. greater than $0.85 .{ }^{9}$ As expected, the Stokes shift, given here by the wavelength difference between the absorbance maximum and the fluorescence maximum, is significantly larger for non-bridged (typically $63 \mathrm{~nm}$ ) than for ring-bridged compounds (typically $40 \mathrm{~nm}$ ) where ring planarity and rigidity are enforced.

\section{Performance Characteristics of New Dyes-General Structural Aspects of Dye Performance}

Referring to Table 2, it can be seen that the alkylated $p$-terphenyl dyes (dyes 3-6,9) are clearly the best from all standpoints. Furthermore, there seems to be no indication from the present work that different alkyl groups ( $t$-butyl, $t$-amyl) have a different effect on the performance parameters. Substitutions at the $4,4^{\prime \prime}$ - or the 3 , $3^{\prime \prime}, 5,5^{\prime \prime}$-positions (see dyes 3-6) enhance the performance characteristics roughly the same. In these cases the solubility of the dyes in $p$-dioxane relative to the parent 
p-terphenyl dye is also enhanced. ${ }^{9}$ Reasons for the enhanced performance of the tertiary alkylated dyes could include the protection of the outer phenyl groups by the bulky alkyl groups from chemical attack. It is curious that the substitution of only one alkyl group (see dyes 3 and 4 ) is sufficient to achieve this effect.

Clearly, direct exocyclic substitution of oxygen onto the aromatic skeleton of the parent molecule, as shown by dyes $2,7,8$, and 10-13, results in unacceptable stability. It is unfortunate that this is the case since this substitution also carries with it polar solvent solubility which might otherwise allow more safe solvent choice. It is apparently not the flexibility alone of the ring-attached alkoxy groups which produces the deleterious effects as shown by the characteristics of the rigidized ether derivatives 12 and 13. Even the remote incorporation of oxygen in an alkoxy side chain group, as shown by dye 9 , results in reduced photochemical stability. Ring bridging with a methylene type linkage, as shown in the very limited comparison of dyes 8 and 10, does not appreciably alter the overall performance of the dye molecule.

The conversion efficiencies of the derivatives vary from 4 to $12 \%$ when pumping at $308 \mathrm{~nm}$. The conversion efficiency is not closely tied to overall photochemical stability since the longest lived dyes do not have the best conversion efficiencies. On the other hand, it is clear here and elsewhere,${ }^{9}$ that relatively high conversion efficiencies $(10-14 \%)$ are required for suitable dye stability in this series of dyes.

\section{Effects of Cover Gases and Circulator Volume on Dye Performance}

In the process of determining the reproducibility of the performance parameters for new $p$-terphenyl dyes it was discovered ${ }^{11}$ that sensitive experimental conditions exist for these dyes in the solvent $p$-dioxane. These conditions included the volume of gas (headspace volume) remaining in the small dye circulators, the number of times the circulator reservoir caps were removed during the photodegradation process, and the temperature of the circulating solvent. In an effort to define the controlling conditions which determined the dye stability, it was found that the composition and the volume of the cover gas above circulating $p$-dioxane dye solutions had a strong effect on the dye lifetime. These effects are not the same for the other solvents studied, and in the case of $n$-heptane solvent, do not seem to be important at all.

\section{Volume of the Cover Gas}

A series of measurements, with varying volumes of circulating dye solution and static air cover gas, were made using the solvent $p$-dioxane. Table 3 shows the results from a carefully controlled single set of measurements made with the dye $p$-terphenyl in $p$-dioxane. As it can be seen, the smallest circulation volume, $100 \mathrm{ml}$, produced the longest dye lifetime. Overall, the dye lifetime is roughly proportional to the headspace volume above the circulating dye solution. In addition, it should be re-emphasized that the numerical value of the dye lifetime for $p$-terphenyl, in particular, is very strongly dependent on the specifics of the solution circulation technique. Thus, the values for the half-life of this dye in the different studies 
presented (compare values in Tables 2, 3, and 5) vary considerably. The lack of sufficient quantities of the remaining $p$-terphenyl dyes discussed in this paper prevented the extension to all the new dyes.

Table 3 Half-life values for the dye $p$-terphenyl in $p$-dioxane with varying circulator solution volumes

\begin{tabular}{lll}
\hline $\begin{array}{l}\text { Solution volume } \\
(\mathrm{ml})\end{array}$ & $\begin{array}{l}\text { Headspace } \\
\text { volume }(\mathrm{ml})\end{array}$ & $\begin{array}{l}E_{1 / 2} \\
\left(\mathrm{~kJ} \cdot \mathrm{l}^{-1}\right)\end{array}$ \\
\hline 100 & 95 & 800 \\
120 & 75 & 625 \\
150 & 45 & 465 \\
195 & 0 & 360 \\
\hline
\end{tabular}

The severe dependence of the $p$-terphenyl dye lifetime in $p$-dioxane solvent on the circulator headspace volume is perplexing. Related experiments which added varying amounts of water to the solvent $p$-dioxane showed that the water component of ambient air is not involved in this effect. Further studies were done to attempt to identify the chemical nature of the dependence on circulator volume as discussed below. It is interesting to note that this same effect is not found in some other ultraviolet dyes, for example, BBQ in $p$-dioxane (see also below).

\section{Effects of Cover Gas Composition on Dye Performance}

In an effort to further define the sensitivity of the $p$-terphenyl $/ p$-dioxane system to the cover gas, a series of studies which varied the composition of the cover gas at fixed solution volume were done. These results are summarized in Table 4. Using the reference system as static air cover gas, it can be seen that circulation of air itself has a positive effect on the dye lifetime. In fact, this circulation can be accomplished by simple insertion of an inexpensive fish aquarium aeration pump in the dye circulation system. That the effect is determined by the mixture of $\mathrm{N}_{2}$ and $\mathrm{O}_{2}$ represented in air is

Table 4 Conversion efficiencies and half-lives for $p$-terphenyl (dye 1) in $p$-dioxane solvent with varying cover gases and fixed $150 \mathrm{ml}$ circulator solution volume

\begin{tabular}{lll}
\hline Cover gas & $\begin{array}{l}\text { Conversion } \\
\text { efficiency }(\%)\end{array}$ & $\begin{array}{l}E_{1 / 2} \\
\left(\mathrm{~kJ} \cdot \mathrm{l}^{-1}\right)\end{array}$ \\
\hline Static & & \\
$\quad$ Air & 12 & 360 \\
Circulated & & \\
$\quad$ Argon & 13 & 270 \\
$\quad$ Bottled air & 12 & 550 \\
$\quad$ Ambient air & 12 & 550 \\
$\quad$ Nitrogen & 13 & 240 \\
Oxygen & 11 & 260 \\
\hline
\end{tabular}


shown by the equivalence of "bottled" air, which contains these two gases only. In a related experiment, a mixture of $2 \%$ oxygen by volume in argon was used as a covergas. The results obtained were the same as for pure argon, suggesting that the effect is not overly sensitive to small amounts of oxygen. Surprisingly, the circulation of any other pure gas tried reduced the dye lifetime considerably.

It is interesting to compare the analogous results for the dye BBQ in $p$-dioxane (Figure 4). In this case it was found that argon enhanced the dye performance while oxygen caused a decreased performance, relative to static or circulated room air. It is important to note in Figure 4 that circulation of air did not have any significant effect on BBQ performance. Thus, it appears that the $p$-terphenyls are strikingly different than other dyes tested in the solvent $p$-dioxane. In an ongoing effort, we have tentatively identified a $p$-terphenyl-dioxane photoproduct in degraded dye solutions. This product seems to be inhibited by the presence of air, thus, giving a plausible explanation for the longer dye lifetimes found for smaller circulation volumes discussed above.

\section{Solvent Choice and Dye Performance}

In a series of studies aimed at finding an alternative solvent to $p$-dioxane for the $p$-terphenyls, several other solvents were examined for use with dyes 1 and 6 . Lack of

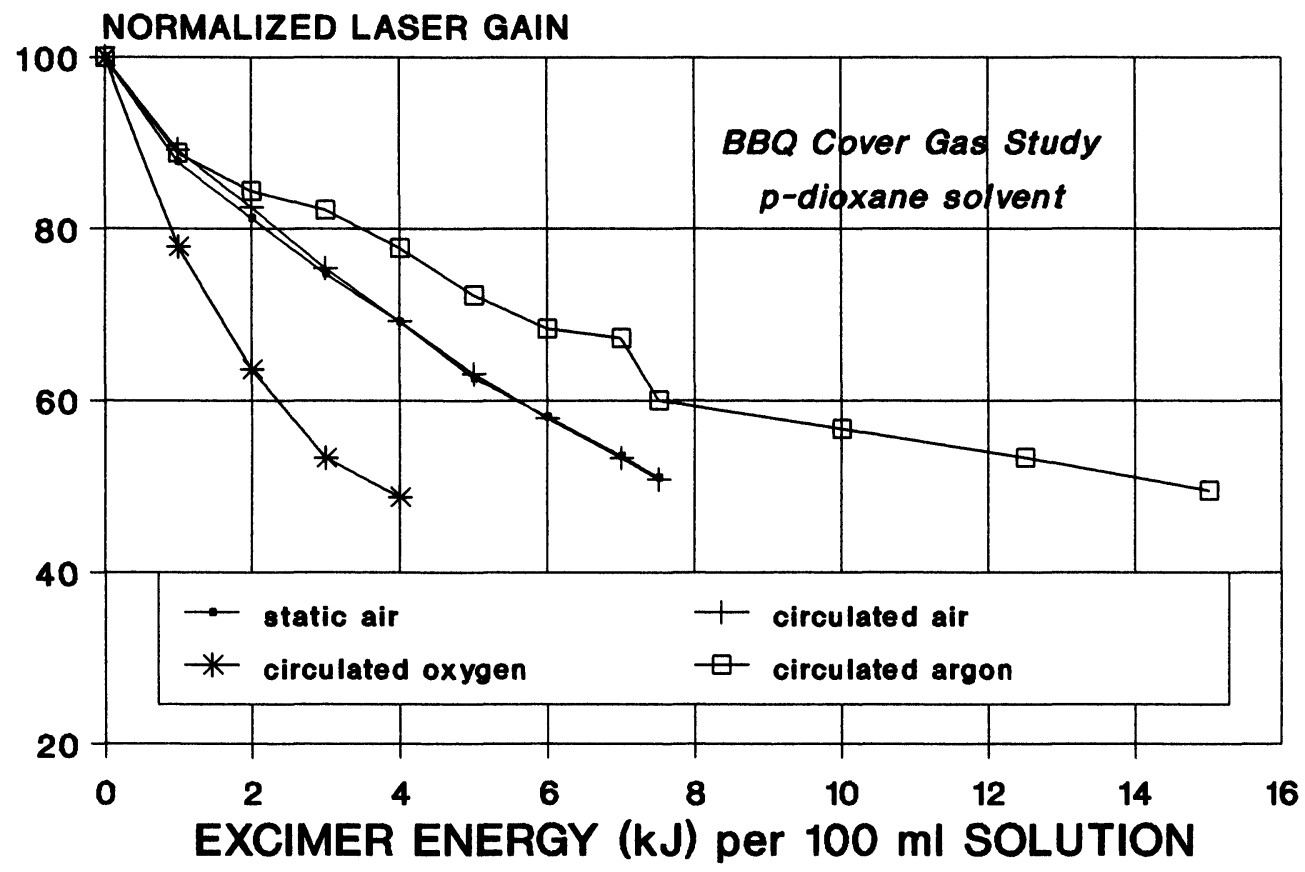

Figure 4 The normalized laser gain at $388 \mathrm{~nm}$ for the dye BBQ in $p$-dioxane solvent $\left(3.7 \times 10^{-4}\right.$ molar $)$ for different flowing cover gases at fixed solution volume $(100 \mathrm{ml})$ versus total excimer laser energy exposure. 
sufficient quantities of the remaining dyes prevented examination of them in the same manner. Table 5 summarizes the results for these two dyes and the chosen solvents. Solvent choices were made for a variety of important characteristics: chemical similarity to $p$-dioxane, glyme; inertness, cyclohexane, $n$-heptane, and iso-octane; solubilizing ability, $N$-methylpyrrolidone. The results clearly show that the only other solvent which approaches the usefulness of $p$-dioxane for these dyes is $n$-heptane. In the case of cyclohexane, the dye laser cuvette windows are too readily etched to make this solvent useful in the Lambda Physik system.

Table 5 Conversion efficiencies and half-lives for $p$-terphenyl (dye 1) and di-t-amyl-p-terphenyl (dye 6) in various solvents

\begin{tabular}{|c|c|c|c|c|}
\hline $\begin{array}{l}\text { Solvent } \\
\text { (solution } \\
\text { volume }^{a}\end{array}$ & $\begin{array}{l}\text { Laser maximum } \\
(\mathrm{nm})\end{array}$ & $\begin{array}{l}\text { Optimum } \\
\text { concentration } \\
\left(\text { mol } \cdot 1^{-1}\right)\end{array}$ & $\begin{array}{l}\text { Conversion } \\
\text { efficiency } \\
(\%)\end{array}$ & $\begin{array}{l}E_{1 / 2} \\
\left(k J \cdot l^{-1}\right)\end{array}$ \\
\hline $\begin{array}{l}p \text {-dioxane }(150 \mathrm{ml}) \\
\text { glyme }(139 \mathrm{ml}) \\
N \text {-methylpyrrolidone }(133 \mathrm{ml}) \\
\text { cyclohexane } \\
n \text {-heptane }(165 \mathrm{ml}) \\
(120 \mathrm{ml})\end{array}$ & $\begin{array}{l}342 \\
341 \\
346 \\
341 \\
341\end{array}$ & $\begin{array}{l}\text { p-terphenyl } \\
1.5 \times 10^{-3} \\
1.2 \times 10^{-3} \\
1.1 \times 10^{-3} \\
1.4 \times 10^{-3} \\
2.0 \times 10^{-3}\end{array}$ & $\begin{array}{r}12 \\
10 \\
7 \\
8 \\
8\end{array}$ & $\begin{array}{l}430 \\
170 \\
110 \\
150 \\
290\end{array}$ \\
\hline $\begin{array}{l}p \text {-dioxane }(122 \mathrm{ml}) \\
\text { iso-octane }(127 \mathrm{ml}) \\
\text { glyme }(122 \mathrm{ml}) \\
\text { cyclohexane }(128 \mathrm{ml}) \\
n \text {-heptane }(185)\end{array}$ & di-t-amyl-p & $\begin{array}{c}-p \text {-terphenyl } \\
0.75 \times 10^{-3} \\
0.87 \times 10^{-3} \\
0.61 \times 10^{-3} \\
0.87 \times 10^{-3} \\
0.82 \times 10^{-3}\end{array}$ & $\begin{array}{l}14 \\
10 \\
11 \\
13 \\
14\end{array}$ & $\begin{array}{l}780 \\
160 \\
160 \\
- \\
240\end{array}$ \\
\hline
\end{tabular}

a Dye solution volume in circulator for results presented.

b Approximate concentration due to poor solubility.

c Amplifier circulator cell etched with extended use.

\section{CONCLUSIONS}

The conclusions from this work for the new dyes under excimer pumping are as follows:

1. Tertiary alkylation of $p$-terphenyl at positions on the exterior phenyl groups results in generally enhanced dye performance including more favorable solubility in $p$-dioxane.

2. Oxygen derivatives are uniformly worse in their performance than the parent dye $p$-terphenyl. Methoxy derivatives have both reduced lifetimes and conversion efficiencies.

3. The solvent $p$-dioxane remains the solvent of choice for the derivatives studied.

4. Cover gas composition and circulation are important determinants in the measurements of dye half-lives for $p$-terphenyl, and by extension, probably at least the remaining alkyl derivatives, in the solvent $p$-dioxane.

5. Enhanced $p$-terphenyl performance in $p$-dioxane can be achieved by simple air cover gas circulation. 


\section{Acknowledgements}

Dye 10 was prepared by C. J. Kelley and A. Ghiorghis, Chemistry Department, Massachusetts College of Pharmacy and Allied Health Sciences, 179 Longwood Avenue, Boston, MLA 02115, by original methods similar to those employed for dyes 12 and 13 in reference 8. This work was supported in part by a grant to CJS and RNS from the State of Ohio Thomas Edison Fund and by the State of Ohio's Academic and Research Challenge Awards to the University of Cincinnati Chemistry Department.

\section{References}

1. H. Telle, W. Huffer and D. Basting, Opt. Comn. 38, 402-406 (1981).

2. W. Huffer, R. Scheider, H. Telle, R. Raue and W. Brinkwerth, Opt. Commn. 33, 85-88 (1980).

3. P. Cossard, P. B. Corkum and A. J. Alcock, Appl. Phys. 25, 17-22 (1981).

4. V. S. Antonov and K. L. Hohla, Appl. Phys. B32, 9-14 (1983).

5. M. Rinke, H. Gusten and H. J. Ache, J. Phys. Chem. 90, 2661-2665 (1986); 90, 2666-2669 (1986).

6. H. Gusten, M. Rinke and H. O. Wirth, Appl. Phys. B45, 279-284 (1988).

7. R. Menzel and H. Lueck, Chem. Phys. 124, 417-424 (1988).

8. J. M. Kauffman, C. J. Kelley, A. Ghiorgiis, E. Neister and L. Armstrong, Laser Chem. 8, 335-348 (1988).

9. C. J. Seliskar, R. N. Steppel and J. M. Kauffman, unpublished results.

10. J. M. Kauffman, C. J. Kelley, A. Ghiorghis, E. Neister, C. J. Seliskar and R. N. Steppel, Proc. Intl. Conf. on Lasers '89, STS Press, McLean, VA, 1990, p. 420.

11. D. J. Schneider, Ph.D. Dissertation, University of Cincinnati, Chemistry Department, 1990. P. A. Fleitz, Ph.D. Dissertation, University of Cincinnati, Chemistry Department, 1988. 